\title{
DEVELOPMENT OF EXFOLIATED LAYERED STANOSILICATE FOR HYDROGEN ADSORPTION
}

\section{Rubio ${ }^{1}$, B. Murillo ${ }^{1}$, C. Casado $^{2}$, A. Mayoral ${ }^{3}$, C. Téllez ${ }^{1}$, J. $^{2}$ Coronas $^{1}$, A. Berenguer-Murcia ${ }^{4}$, D. Cazorla-Amorós ${ }^{4}$}

${ }^{1}$ Department of Chemical and Environmental Engineering and Nanoscience Institute of Aragón (INA), Universidad de Zaragoza, 50018 Zaragoza. Spain

${ }^{2}$ Department of Chemical Engineering and Inorganic Chemistry, Universidad de Cantabria, 39005 Santander, Spain

${ }^{3}$ Laboratorio de Microscopias Avanzadas (LMA), Nanoscience Institute of Aragón (INA), Universidad de Zaragoza, 50018 Zaragoza. Spain

4 Alicante Materials Institute and Inorganic Chemistry Department, University of Alicante, 03080 Alicante, Spain 


\section{Abstract}

The use of hydrogen as an energy vector involves among other steps storage. This has caused the development of new materials with high hydrogen adsorption capacity. In this field, new layered stannosilicate, called UZAR-S3, has been synthesized and delaminated becoming UZAR-S4. The new materials have been characterized by several techniques: XRD, XRF, SEM, TEM, TGA, adsorption of $\mathrm{N}_{2}, \mathrm{H}_{2}$ and $\mathrm{CO}_{2}, \mathrm{Hg}$ porosimetry, ${ }^{29}$ Si NMR MAS and ${ }^{119}$ Sn NMR MAS. UZAR-S3, with empirical formula $\mathrm{Na}_{4} \mathrm{SnSi}_{5} \mathrm{O}_{14} \cdot 5 \mathrm{H}_{2} \mathrm{O}$ and lamellar morphology, is a layered stannosilicate built from $\mathrm{SnO}_{6}$ and $\mathrm{SiO}_{4}$ polyhedra. The delamination process used here comprises three stages: protonation with acetic acid, swelling with nonylamine and the delamination itself with an $\mathrm{HCl} / \mathrm{H}_{2} \mathrm{O} /$ ethanol solution. UZAR-S4 is composed of sheets of a few nanometers of thickness with a high aspect ratio and BET surface area of $236 \mathrm{~m}^{2} / \mathrm{g}$ twenty times higher than for UZAR-S3. At $-196{ }^{\circ} \mathrm{C}, \mathrm{H}_{2}$ adsorption is measured reaching remarkable values of 3.7 and 4.2 wt\% for 10 and 40 bar, respectively, the last value giving a high volumetric $\mathrm{H}_{2}$ storage capacity of $26.2 \mathrm{~g}$ of $\mathrm{H}_{2} / \mathrm{L}$.

Keywords. Hydrogen storage, Layered stannosilicates, Delaminated materials 


\section{Introduction}

In recent years, efforts have been devoted to synthesize new crystalline microporous structures, different from classical zeolites, for their application in gas storage, separation and purification fields. A large number of studies have been concerned with microporous mixed Octahedral-Pentahedral-Tetrahedral (OPT) framework silicates [1]. They have a crystal structure consisting of $\mathrm{TO}_{4}$ tetrahedral units $(\mathrm{T}=\mathrm{Si}, \mathrm{Ge})$ and polyhedra $\mathrm{MO}_{\mathrm{n}}(\mathrm{n}=5,6),(\mathrm{M}=\mathrm{Sn}, \mathrm{Ti}, \mathrm{Zr}, \mathrm{V}, \mathrm{Nb})$. Within microporous OPT titanosilicates stand out ETS-10 [2], ETS-4 [3] and umbite-type compounds [4], about which a large number of research papers have been developed. Several OPT stannosilicates have been also reported: Sn-A, Sn-B, Sn-L [5], AV-6 [6], AV-7 [7], AV-10 [8], Sn-AV-11 [9], Sn-AV-13 [10], Sn-AV-14 [11], $\mathrm{Cs}_{2} \mathrm{SnSi}_{3} \mathrm{O}_{9}$ [12] and EMS-2 [13].

Porous layered silicates are now a developing research area because of the advantages of layered materials as active catalysis [14], enhancing the permselectivity of polymer-zeolite nanocomposite membranes [15] and producing polymer-layered silicate nanocomposites with improved tensile properties [16]. A characteristic process of some layered materials is their swelling and delamination which involves the intercalation of guest molecules to increase the interlayer space and subsequent exfoliation. These reactions are interesting in the case of few known layered zeolites: EU-19 [17], PREFER [18], MCM-22P [19], Nu-6 (1) [20] obtaining delaminated zeolites EU-20 [21], ITQ-2 [22], ITQ-6 [23], ITQ-18 [24] and Nu-6 (2) [25]. Also, layered titanosilicates have been delaminated, such as JDF-L1 [26] and AM-4 [27] obtaining the delaminated titanosilicates called UZAR-S1 [28] and UZAR-S2 [29]. Regarding layered OPT stannosilicate Corcoran et al. in 1989 [5] report a job involving 
the synthesis of the first layered material, named Sn-L. There are other porous layered stannosilicate, Sn-Ilerite [30], although its sheets are only formed by tetrahedral units.

Another area of research in constant development is materials with high capacity to adsorb gases. Among the studied gases, hydrogen is particularly relevant because it is becoming increasingly important as an energy vector. One of the main reasons is because the main renewable energy sources in nature, such as solar, wind and geothermal, generally need to be transformed into electricity to be transported efficiently. Alternatively, hydrogen must only be produced. This production can be made from renewable energy sources and subsequently convert it to electricity through the use of fuel cells [31]. Conventional storage of large quantities of hydrogen in its molecular form is complex and expensive due to the need to use high pressures and low temperatures in order to have a high energy density that approaches commercial parameters. This causes an enormous effort in the development of materials and techniques efficient enough to allow use in both stationary and mobile applications. In this development of new materials with high hydrogen adsorption capacity stand out from other activated carbons [31-33] and MOFs [34, 35].

We present in this paper the synthesis of a novel stannosilicate named UZARS3, its swelling and subsequent exfoliation resulting in a new delaminated material named UZAR-S4. These materials have been characterized by multiple characterization techniques and they have been applied to hydrogen adsorption.

\section{Experimental section}

\subsection{Preparation of materials}


To prepare $19.1 \mathrm{~g}$ of gel, sodium silicate solution $\left(27 \mathrm{wt} \% \mathrm{SiO}_{2}, 8 \mathrm{wt} \% \mathrm{Na}_{2} \mathrm{O}\right.$, Merck) (10.0 g) was mixed with deionized water (6,5 g) and $\mathrm{NaOH}$ (98 wt\%, SigmaAldrich) (1.4 g); then tin(II) chloride dihydrate (reagent grade 98 wt\%, Sigma-Aldrich) (1.2 g) was added. After stirring for half an hour at room temperature, the resulting gel was degassed for a few minutes in ultrasonic bath and transferred into a $40 \mathrm{~mL}$ Teflonlined autoclave. The crystallization was carried out under hydrothermal conditions at $230{ }^{\circ} \mathrm{C}$ for $96 \mathrm{~h}$. After filtering and washed repeatedly with deionized water and dried at $100{ }^{\circ} \mathrm{C}$ overnight, ca. $4.4 \mathrm{~g}$ of powder was obtained.

This material, called UZAR-S3, is swollen by intercalation of nonylamine molecules. Previous to this step there was a proton exchange procedure of the material $(0.66 \mathrm{~g})$ with a solution of water and acetic acid $(0,38 \mathrm{~g}$ of glacial acetic acid in 82,5 $\mathrm{mL}$ of deionized water, $\mathrm{pH}=2.7$ ) for $10 \mathrm{~min}$, after this time the $\mathrm{pH}$ reached a value of 3.9 (sample H- UZAR-S3). After this time the solution of nonylamine (5.42 $\mathrm{g}$ in $165 \mathrm{~mL}$ of deionized water) was added and the reaction was carried under reflux at $60{ }^{\circ} \mathrm{C}$ for $14 \mathrm{~h}$ with a constant $\mathrm{pH}$ of 9.6. Finally the solution was centrifuged in order to recover the solid with acetone and it was dried at $70{ }^{\circ} \mathrm{C}$ for $3 \mathrm{~h}$ obtaining the swollen material.

The delaminated material (UZAR-S4) was obtained by extracting the amine with an $\mathrm{HCl} / \mathrm{H}_{2} \mathrm{O} / \mathrm{ethanol}$ (5:17:870, molar ratio) solution. This extraction is carried under reflux for $8 \mathrm{~h}$ and $55^{\circ} \mathrm{C}$. After this time, the solid was recovered, washed 5 times with deionized water and dried to $100{ }^{\circ} \mathrm{C}$ for $12 \mathrm{~h}$.

\subsection{Characterization}

X-ray diffraction (Rigaku/Max System diffractometer, $\mathrm{CuK} \alpha$ radiation with $\lambda=1.5418 \AA$ and graphite monochromator) and X-ray fluorescence analyses (THERMO ELECTRON ARL ADVANT'XP equipped with a rhodium tube and software 
UNIQUANT) were conducted for most of the samples. Thermogravimetric analyses (TGA) were performed in a TGA/DSC 1 STAR $^{\mathrm{e}}$ SYSTEM (Mettler Toledo) under air at a heating rate of $10^{\circ} \mathrm{C} / \mathrm{min}$.

Scanning electron microscopy (JEOL JSM 6400) images were obtained over gold-coated specimens by operating at $20 \mathrm{kV}$, while images of the smallest crystals were collected using transmission electron microscopy (JEOL-2000 FXII). TEM specimens were prepared after repeated dispersion in acetone before pouring onto the carbon grid.

The measurements of ${ }^{29} \mathrm{Si}$ NMR MAS were carried out with a pulse of $90^{\circ}$, a recycle delay of $5 \mathrm{~s}$ and a spinning rate of $10 \mathrm{kHz}$. Chemical shifts referred to 3(trimethylsilyl)-1-propanesulfonic acid. In the case of ${ }^{119} \mathrm{Sn}$ NMR MAS, they were measured with a pulse of $40^{\circ}$, a recycle delay of $100 \mathrm{~s}$ and a spinning rate of $12 \mathrm{kHz}$. Chemical shifts referred to tin dioxide. Fourier transformed infrared (FTIR) transmission spectra were measured on a Shimadzu IRAffinity-1 in the range of 400$4000 \mathrm{~cm}^{-1}$ using a $\mathrm{KBr}$ wafer, resolution $4 \mathrm{~cm}^{-1}$ and 30 scans.

To analyze the porosity a Micrometrics Tristar 3000 instrument was used with two adsorbates: $\mathrm{N}_{2}$ at $-196{ }^{\circ} \mathrm{C}$ and $\mathrm{CO}_{2}$ at $25{ }^{\circ} \mathrm{C}$. The samples were measured after degassing them at $200{ }^{\circ} \mathrm{C}$ for $8 \mathrm{~h}$. Mercury porosimetry experiments were performed using a Micromeritics Autopore IV 9520 capable of obtaining pressures of $414 \mathrm{MPa}$. Samples were degassed for 24 hours at $100{ }^{\circ} \mathrm{C}$ and all penetrometers were calibrated and the baseline errors of each penetrometer, caused by the compressibility and thermal effects of the mercury and penetrometer parts, were obtained from analysis without sample. 
Hydrogen isotherms at $-196^{\circ} \mathrm{C}$ and up to $4 \mathrm{MPa}$ were obtained using a Sartorius 4406 DMT high-pressure microbalance. The sample was degassed at $150^{\circ} \mathrm{C}$ overnight under vacuum. The experimental results were corrected for buoyancy effects related to the displacement of gas by the sample, the sample holder, and the pan.[Agarwal, R.; Schwarz, J. Analysis of high-pressure adsorption of gases on activated carbon by potential-theory. Carbon 1988, 26, 873-87] Hydrogen isotherms at $25^{\circ} \mathrm{C}$ were determined in an automatic volumetric apparatus designed and assembled at the Departamento de Química Inorgánica, Universidad de Alicante laboratory to determine hydrogen isotherms up to $20 \mathrm{MPa}$. The manifold of the apparatus was kept at $36^{\circ} \mathrm{C}$. Also, the sample cell was refrigerated at $25^{\circ} \mathrm{C}$ by means of a liquid bath. The manifold volume was calibrated with a standard volume by determining helium isotherms. To ensure that the apparatus was leakfree, a hydrogen leak test was executed at 9 and 15 MPa over $28 \mathrm{~h}$, with a leak rate of less than $10^{-6} \mathrm{~s}^{-1}$ resulting. The bulk gas amounts were calculated by the equation of state of the modified Benedic-Webb-Rubin [Zhang, C.; Lu, X. S.; Gu, A. Z. How to accurately determine the uptake of hydrogen in carbonaceous materials. Int. J. Hydrogen Energ. 2004, 29, 1271-1276] formalism, and the cell volume has been calculated by taking into account the correction described in the literature.[Kiyobayashi, T.; Takeshita, H. T.; Tanaka, H.; Takeichi, N.; Zuttel, A.; Schlapbach, L.; Kuriyama, N. Hydrogen adsorption in carbonaceous materials. J. Alloys Compd. 2002, 330, 666-669] Previous to the determination of the adsorption isotherm, the sample was degassed at $150^{\circ} \mathrm{C}$ for $4 \mathrm{~h}$ under vacuum. After that, the sample was placed in the sample holder and then evacuated at $130^{\circ} \mathrm{C}$ for $4 \mathrm{~h}$ in vacuum. The sample weight was about $500 \mathrm{mg}$. Hydrogen and helium gases used in the experiments were 99.9995\% pure. In both experimental systems used for hydrogen adsorption measurements, the excess hydrogen adsorption is obtained and these are the 
values reported in this work. Solid-state NMR MAS spectra were recorded with a Bruker AV400 WB spectrometer operating at a resonance frequency of $79.49 \mathrm{MHz}$ and with a $4 \mathrm{~mm}$ probe.

\section{Results}

\section{Layered stannosilicate UZAR-S3}

UZAR-S3 is a white solid that, to the best of our knowledge, can be identified by a unique X-ray diffraction pattern shown in Fig. 1 and table S1 (supporting information). This diffractogram was compared with the diffractograms of reported OPT stannosilicates showing obvious difference in d- spacings (see Table S2, supporting information). By scanning electron microscope (Fig. 2a,b), it is observed that UZAR-S3 exhibits mainly spherical aggregates formed by sheets. These sheets have a size of 3-4 $\mu \mathrm{m}$ with a thickness of ca. $100 \mathrm{~nm}$.

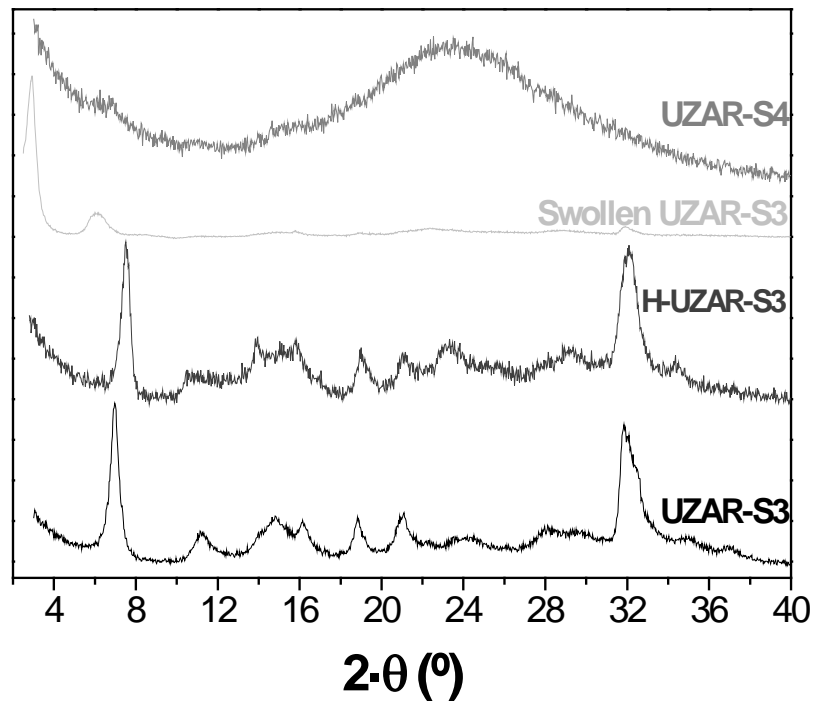

Figure 1. XRD of UZAR-S3, swollen UZAR-S3 and UZAR-S4 

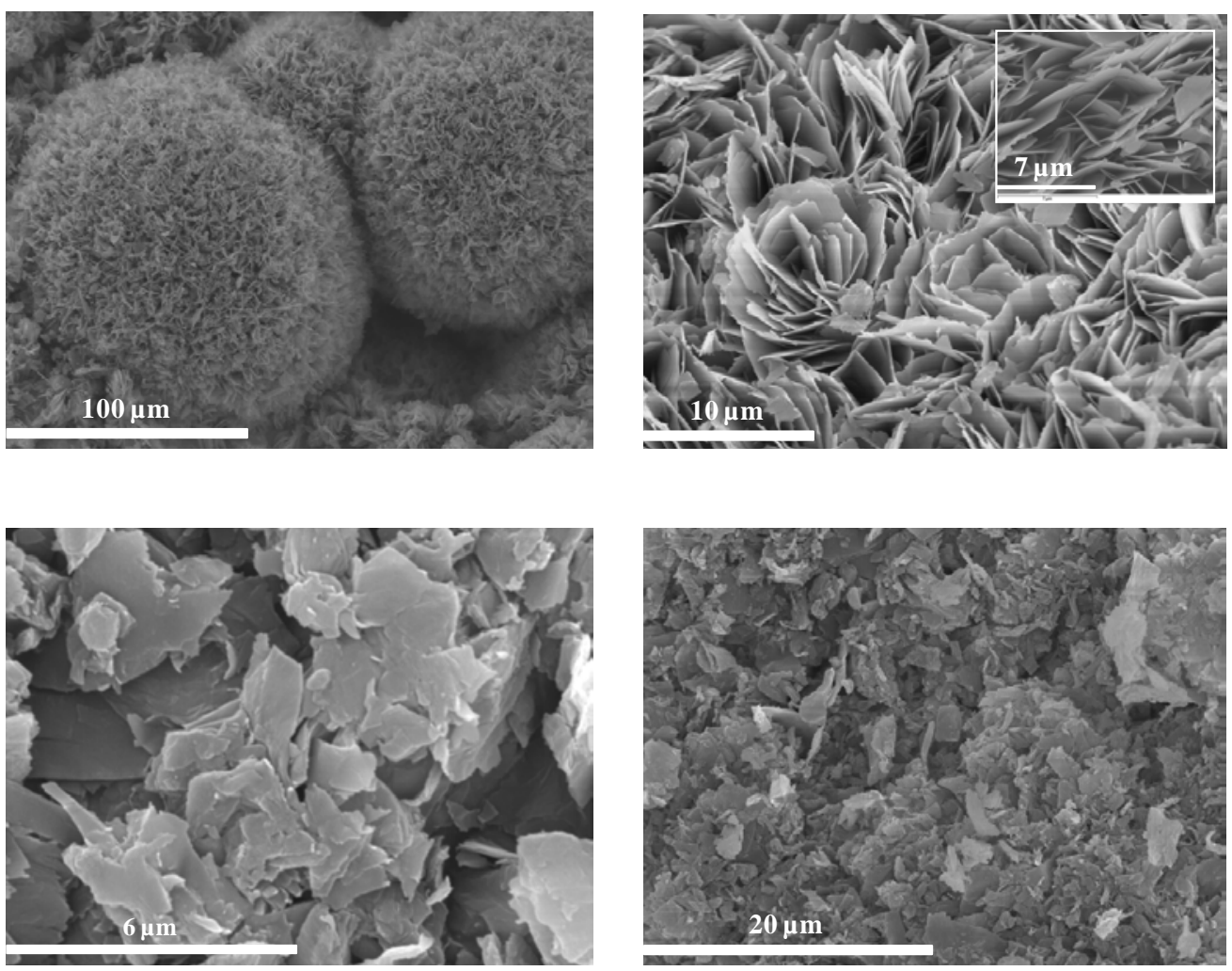

Figure 2. SEM Images of UZAR-S3 ( $a, b)$, swollen UZAR-S3 (c) and UZAR-S4 (d)

In order to establish the molecular formula of UZAR-S3, three samples were analyzed by X-ray fluorescence and thermogravimetric analyses to determine metal and water composition, respectively. X-ray fluorescence gives $\mathrm{Na} / \mathrm{Sn}$ and $\mathrm{Si} / \mathrm{Sn}$ atomic ratios ca. $3.7 \pm 0.3$ and $4.7 \pm 0.2$, respectively. For UZAR-S3, water weight loss took place below $300{ }^{\circ} \mathrm{C}$ with a maximum weight loss at $100{ }^{\circ} \mathrm{C}$ representing $9.6 \pm 0.5 \mathrm{wt} \%$, as shown in Fig. 3. Balancing oxygen with $\mathrm{Na}^{+}, \mathrm{Si}^{4+}$ and $\mathrm{Sn}^{4+}$, the molecular formula of UZAR-S3 can be estimated as: $\mathrm{Na}_{4} \mathrm{Sn} \mathrm{Si}_{5} \mathrm{O}_{14} \cdot 3.5 \mathrm{H}_{2} \mathrm{O}$. This molecular formula is different from the molecular formula that present other stannosilicates (see table S2, supporting information) although very similar to the formula of Sn-L reported by Corcoran et al. [5] but these material present a different crystal structure as confirmed by XRD and further corroborated with other characterization techniques. 


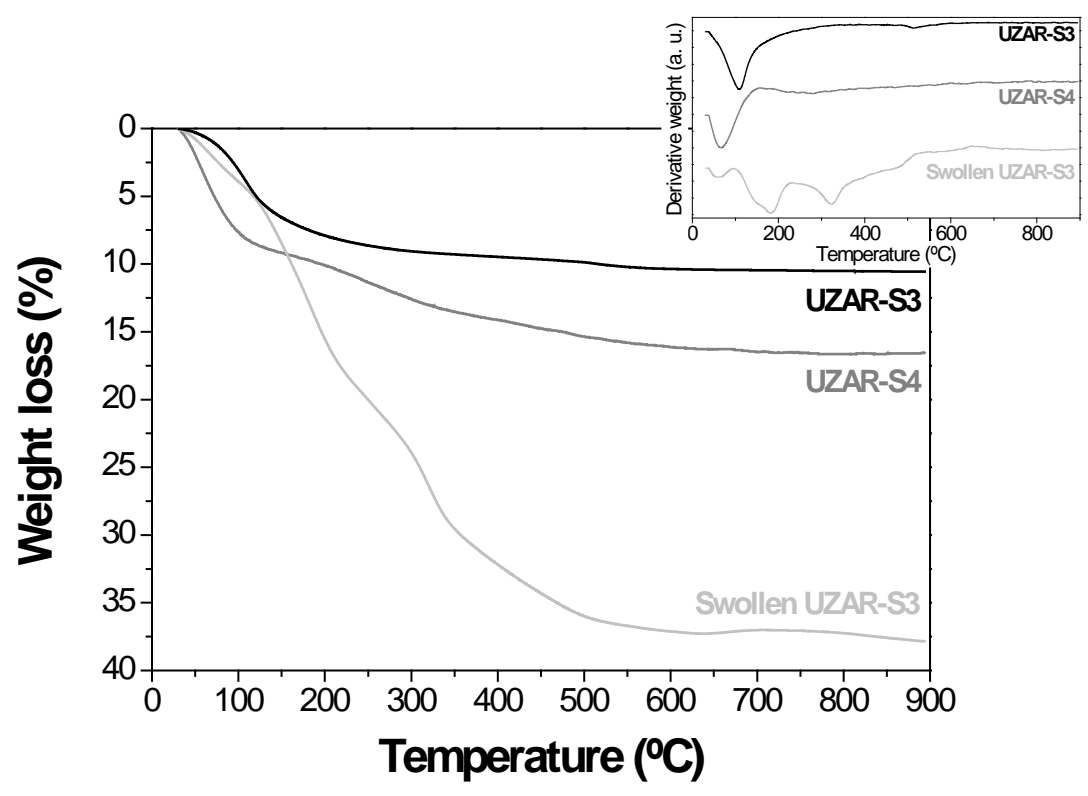

Figure 3. TGA of UZAR-S3, swollen UZAR-S3 and UZAR-S4. Inset: Derivative TGA graphs

In the UZAR-S3 X-ray diffraction pattern, the first peak at 2 theta $=6.97^{\circ}$ could manifest layered structure, using Bragg's law gives a d-spacing between the planes of $1.3 \mathrm{~nm}$. In order to corroborate the layered structure, swelling was conducted using a successful recipe used with other layered titanosilicates (JDF-L1 [28] and AM-4 [29]). To favor the intercalation of molecules, the layered material was protonated in the presence of acetic acid and after this it is swollen using nonylamine. Protonated and swollen UZAR-S3 were analyzed by XRD (Fig. 1) to study how these two processes, protonation and swelling, affected to the crystalline structure of the material. All the XRD reflections in the UZAR-S3 are present in its protonated form even though very small changes in the intensity are evident. Swollen UZAR-S3 displays a first peak at 2theta $=2.95^{\circ}$ characteristic of swollen materials, Bragg's law gives a d-spacing between the planes of $3.0 \mathrm{~nm}$. In TGA (Fig. 3), it is observed that the weight loss in the swollen material is greater than in the pristine one. This is due to the presence of nonylamine in the material (33.0 wt\%). This amount is comparable to the amount of nonylamine 
intercalated in the titanosilicate JDF-L1 (with similar atomic spacing $3.0 \mathrm{~nm}$ ), indicating a bilayer surfactant configuration [28]. This total amount of amine can be divided into two parts: the first from 150 to $275^{\circ} \mathrm{C}$ due to the protonated amine and the second from $275^{\circ} \mathrm{C}$ attributed to nonprotonated amine. This distinction, is similar to that occurring in the case of zeolite MCM-22P laminar [19]. The d-spacing between the layers in swollen UZAR-S3 is corroborated by TEM as is shown in Fig. 4a. Therefore, it is found that UZAR-S3 is a laminar material and the swelling process shown is effective.
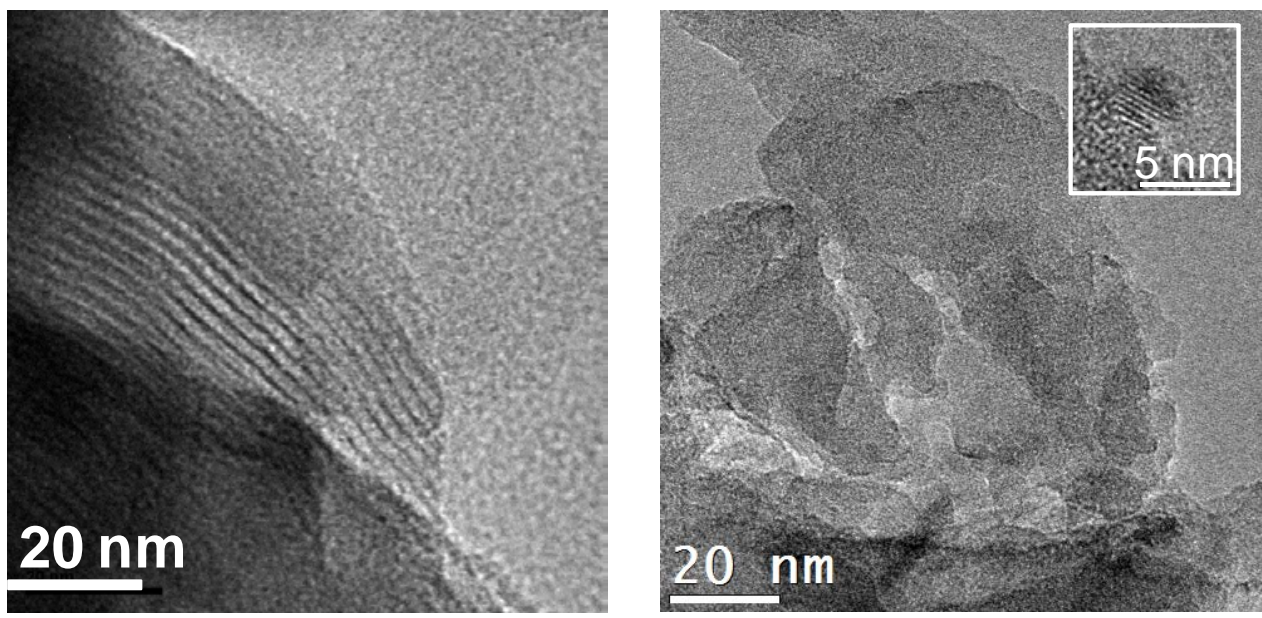

Figure 4. TEM Images of swollen UZAR-S3(a) and UZAR-S4 (b)

NMR analyses were performed in order to obtain structural information of this new stannosilicate. ${ }^{119}$ Sn NMR spectra of UZAR-S3 (Fig. 5a) shows one peak at -692.9 ppm ascribed to the single $\mathrm{Sn}(6 \mathrm{Si})$ environment present [7]. ${ }^{29} \mathrm{Si}$ NMR spectra of UZAR-S3 (Fig 5b) shows three peaks at -80.1 , -82.8 and -86.7 ppm (areas ratio ca. 1.5:1:2). These values of resonance are in the same order of magnitude as those reported for other stannosilicates but regarding number of peaks and population differences are evident even with the stannosilicate Sn-L (see table S3, Supporting information). The peak at -86.7 ppm might belong to two sites $\mathrm{Si}(2 \mathrm{Si}, 2 \mathrm{Sn})$ [12] and the peak at $-82.8 \mathrm{ppm}$ 
to a single site $\mathrm{Si}(2 \mathrm{Si}, 2 \mathrm{Sn})$ [5]. The resonance at $-80.1 \mathrm{ppm}$ can be assigned as $\mathrm{Si}(2 \mathrm{Si}$, 1Sn). So, UZAR-S3 shows four sites of $\mathrm{Si}$ : one site $\mathrm{Q}^{3}$ (2Si, $\left.1 \mathrm{Sn}\right)$ and 3 sites $\mathrm{Q}^{4} \mathrm{Si}(2 \mathrm{Si}$, 2Sn) with an area ratio of 1.5:1:1:1 respectively. The site $\mathrm{Si}(2 \mathrm{Si}, 1 \mathrm{Sn})$ is new in this type of materials, showing a $\mathrm{Q}^{3}$ position typical of laminar materials [28], it is due to the presence of small and thin particles in which the rupture of bonds $\mathrm{Si}-\mathrm{O}-\mathrm{Si}$ has taken place. This Si would show two bonds $-\mathrm{O}-\mathrm{Si}$, one $-\mathrm{O}-\mathrm{Sn}$ and other $-\mathrm{O}-\mathrm{H}$. The small amount of $\mathrm{Sn}$ in this site makes that only one peak is observed in the ${ }^{119} \mathrm{Sn} \mathrm{NMR}$ spectra. It is like the material EMS-2 [13] that has $\mathrm{Si}(2 \mathrm{Si}, 2 \mathrm{Sn}), \mathrm{Si}(3 \mathrm{Si}, 1 \mathrm{Sn})$ and a single site $\mathrm{Sn}(6 \mathrm{Si})$. The NMR analysis indicates that the framework of UZAR-S3 consists of $\mathrm{SnO}_{6}$ octahedra and $\mathrm{SiO}_{4}$ tetrahedra and can be classified in the OPT family.
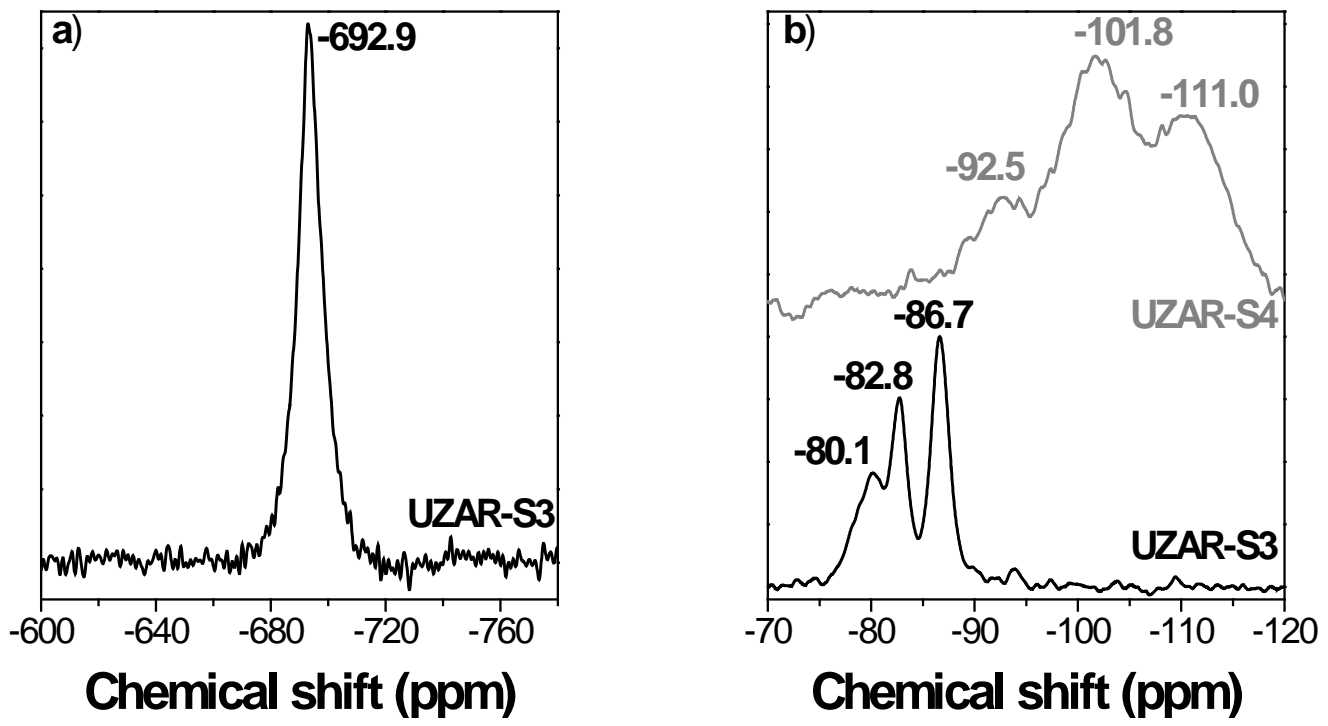

Figure 5: a) ${ }^{119}$ Sn MAS NMR of UZAR-S3. b) ${ }^{29}$ Si MAS NMR of UZAR-S3 and UZAR-S4 ;

In order to check the porosity, as made, protonated and swollen UZAR-S3 samples, scarcely adsorbs $\mathrm{N}_{2}$, and this is reflected by a BET specific surface area of $10.5 \pm 5.6 \mathrm{~m}^{2} / \mathrm{g}$ (3 samples), $7.1 \pm 0.1 \mathrm{~m}^{2} / \mathrm{g}$ and $19.7 \pm 0.1 \mathrm{~m}^{2} / \mathrm{g}$, respectively. It should 
be noted that these results do not indicate that the material is non-porous. What these results can tell is that the pores are smaller than the kinetic diameter of the nitrogen molecule $(0.364 \mathrm{~nm})$ as occurs with other microporous OPT titanosilicates (umbite and JDF-L1).

\section{Exfoliated stannosilicate UZAR-S4}

Swollen UZAR-S3 was exfoliated by $\mathrm{HCl}$ extraction to get the exfoliated stannosilicate UZAR-S4. After this chemical extraction, UZAR-S4 shows a XRDamorphous or exhibits broad reflections (Fig. 1), similar to other delaminated porous materials [24].

The delaminated stannosilicate has also been characterized by thermogravimetric analysis (Fig. 3). At temperatures below $150{ }^{\circ} \mathrm{C}$ the weight loss is greater than UZAR-S3 because the delaminated material adsorbs more moisture by the most exposed area. The weight loss after $175{ }^{\circ} \mathrm{C}$ could suggest that removal of the amine material has not been completed but maximum weight loss does not agree with the swollen UZAS-S3. To clarify FTIR analyses have been done (Fig. S1, supporting information), the bands at 2958, 2926, 2855 and $1558 \mathrm{~cm}^{-1}$ assigned to the presence of amine, due to $\mathrm{C}-\mathrm{H}$ bond stretching of $-\mathrm{CH}_{2}-$ and $-\mathrm{CH}_{3}$ groups and $-\mathrm{NH}_{2}$ functional do not appear in sample UZAR-S4 indicating that the extraction process is adequate to remove the main portion of nonylamine.

Nitrogen adsorption isotherms of materials are compared in Fig. 6. The adsorption isotherms for UZAR-S3 and swollen UZAR-S3 show a very small $\mathrm{N}_{2}$ adsorption but the nitrogen isotherm of UZAR-S4 indicated a wide pore-size distribution ranging from micro to mesopores. The BET specific surface area was $236 \pm$ $28 \mathrm{~m}^{2} / \mathrm{g}$ (mean value and standard deviation of 4 samples prepared in the same 
conditions, with minimum and maximum values 203 and $269 \mathrm{~m}^{2} / \mathrm{g}$ ). This means a BET specific surface area twenty times higher for UZAR-S4 than for UZAR-S3. The tmethod was employed for estimating the external surface area of the samples. The internal or microporous surface area could be obtained by subtracting the external surface area from the BET surface area. The corresponding t-plot analysis of UZAR-S4 nitrogen isotherm gave an external and internal surface area of $108 \pm 32 \mathrm{~m}^{2} / \mathrm{g}$ and $129 \pm$ $13 \mathrm{~m}^{2} / \mathrm{g}$, respectively, again as mean values and standard deviation for a batch of 4 samples. These results are in agreement with the successful exfoliation process that makes the surface of the material more accessible, both, the external surface area of the exfoliated layers and the internal surface area of the material.

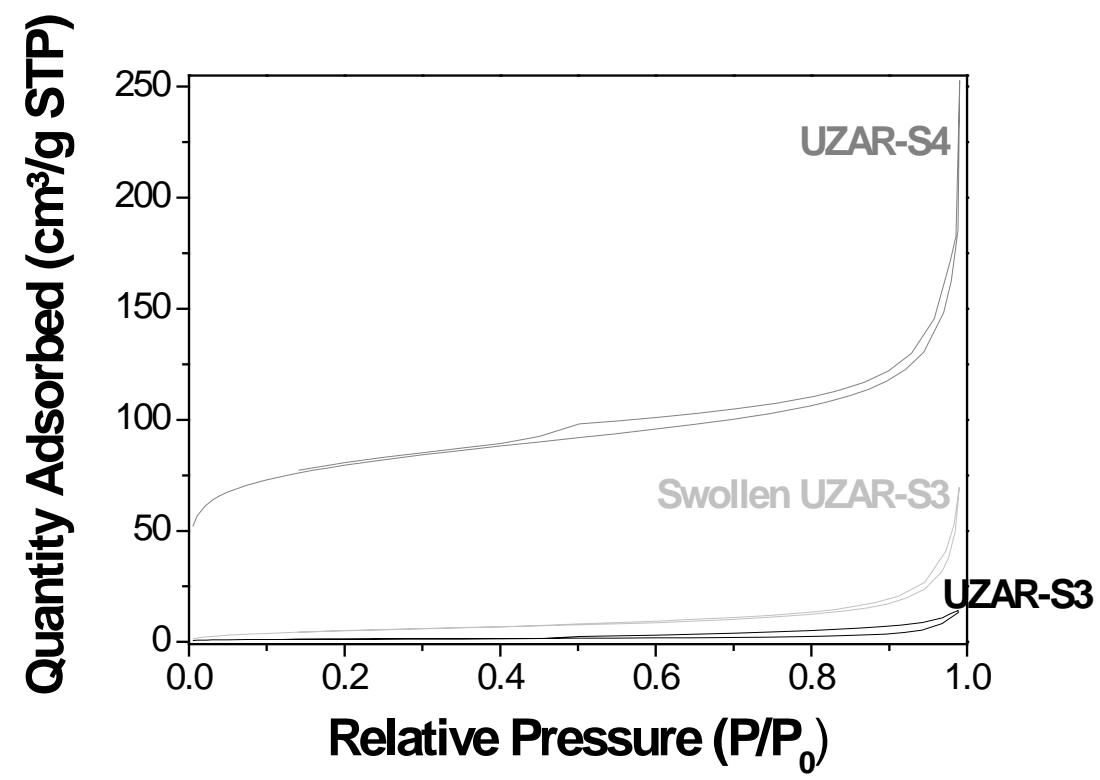

Figure 6. $\mathrm{N}_{2}$ adsorption/desorption of UZAR-S3, swollen UZAR-S3 and UZAR-S4 at $196{ }^{\circ} \mathrm{C}$

$\mathrm{CO}_{2}$ adsorption isotherms were performed at $25{ }^{\circ} \mathrm{C}$ to the as-synthesized and delaminated stannosilicate (Fig. S2, supporting information). These results corroborate $\mathrm{N}_{2}$ adsorption, UZAR-S4 has a $\mathrm{CO}_{2}$ adsorption capacity 15 times greater than UZARS3. Comparing these results with other materials the maximum value obtained for 
UZAR-S4 (0.7 mmol CO $\left.\mathrm{CO}_{2} / \mathrm{g}\right)$ is less than ETS-10 (2 $\left.\mathrm{mmol} \mathrm{CO}_{2} / \mathrm{g}\right)$ [36], similar to $\mathrm{Sn}$ Umbite (0.9 mmol CO $\left.\mathrm{CO}_{2} / \mathrm{g}\right)$ [37] and greater than Ti-Umbite $\left(0.2 \mathrm{mmol} \mathrm{CO}_{2} / \mathrm{g}\right)$ [37] and

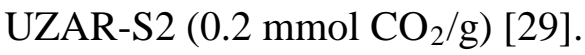

The delaminated material was analyzed by mercury porosimetry with the aim of determine the variation in the macro- and mesoporosity with respect to the synthesis, these results are shown in Fig. 7. It is found that UZAR-S4 has a higher specific pore volume than UZAR-S3. The most significant difference is the creation of pores with a diameter greater than $20 \mathrm{~nm}$, this is also seen in delamination of other materials such as vermiculite [38], and may be due to the space created between particles of exfoliated UZAR-S3. The difference observed for diameters of pore between 10 and $1 \mu \mathrm{m}$ is because at low pressure mercury is penetrating into the interparticle spaces [39] being higher in the case of delaminated material, since the number of layers increases for same amount of solid thus increasing the volume of the gaps created between them. For higher pressures (diameters between $1 \mu \mathrm{m}$ and $200 \mathrm{~nm}$ ), mercury envelops the particles and starts to compress them [39] showing a greater volume of mercury used in the case of the delaminated material again due to the dispersion of the sheets.
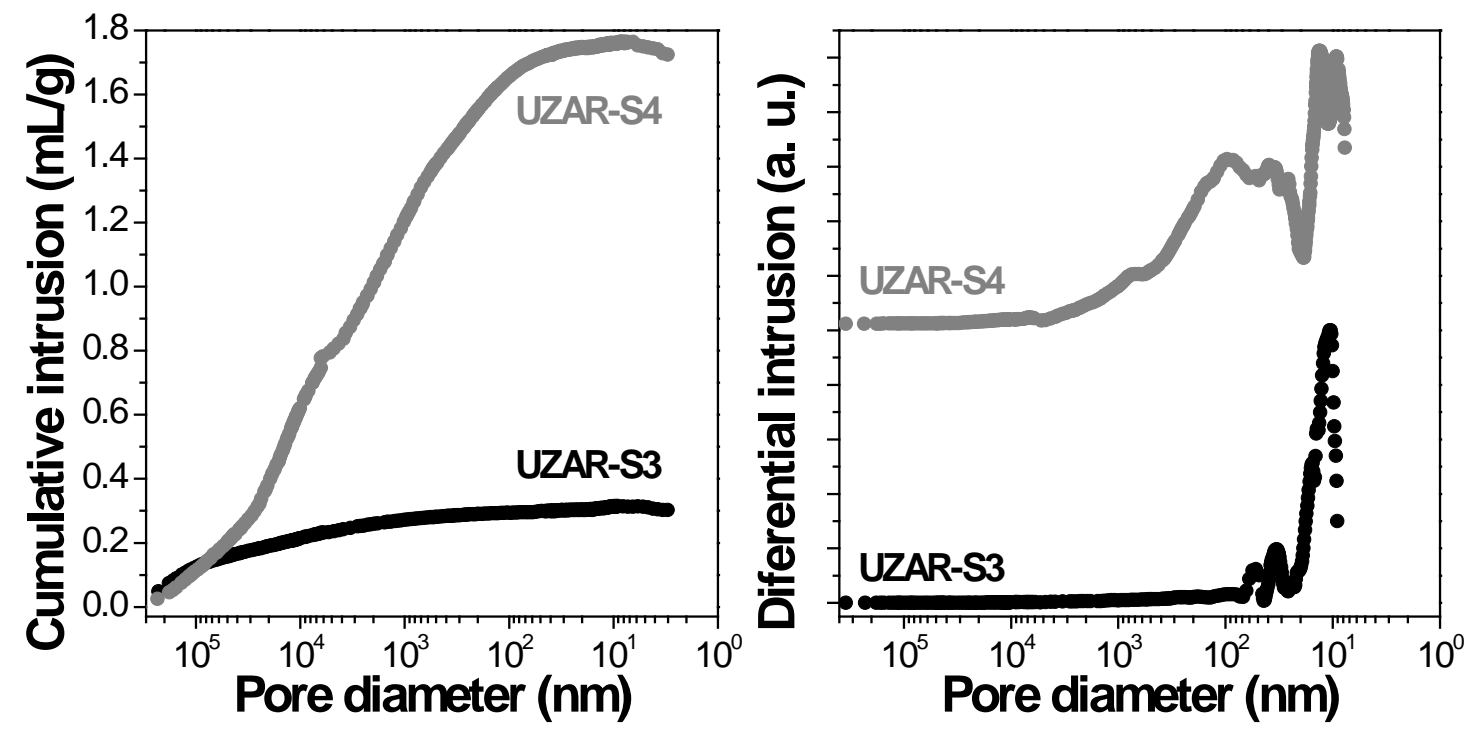
Figure 7. Hg porosimetry of UZAR-S3 and UZAR-S4

To gain more insight in the exfoliation process, a study of electron microscopies has been realized. SEM images of UZAR-S4 (Fig 3d) did not show the aggregates of UZAR-S3 presenting broken micrometric sheets with nanometric thickness. These are also appreciable in the images of TEM in Fig. 4b. In the inset of this figure, the basal spacing observed is $3.3 \AA$.

${ }^{29}$ Si MAS NMR spectra were performed in order to obtain structural information on the connectivity of $\mathrm{TO}_{4}$ tetrahedral where $\mathrm{T}$ would in this case $\mathrm{Si}$ or $\mathrm{Sn}$ and oxygen could be connected to other metal atoms or protons. In Fig. 5b the differences between UZAR-S3 and UZAR-S4 can be observed. UZAR-S4 maintains the three positions of UZAR-S3 but moved toward lower values of chemical shift. For UZAR-S4 there are three chemical shifts at $-92.5,-101.8$ and $-111.0 \mathrm{ppm}$, values very close to those seen in the titanosilicate UZAR-S1[28]. As in the case of UZAR-S1, sites $\mathrm{Si}(2 \mathrm{Si}, 1 \mathrm{Me})$ and $\mathrm{Si}(1 \mathrm{Si}, 1 \mathrm{Me})$ are generated by the rupture of the Si-O-Si consistent with the fine particles observed by TEM. Sites $\mathrm{Si}(3 \mathrm{Si}, 0 \mathrm{Me})$ and $\mathrm{Si}(4 \mathrm{Si}, 0 \mathrm{Me})$ could be the result of chemical attack taking place on the tin throughout the process and for this reason, no signal was observed in the ${ }^{119}$ Sn MAS NMR analysis (not shown). The leaching of Sn after the chemical extraction of UZAR-S4 was confirmed by X-ray fluorescence. $\mathrm{Na} / \mathrm{Sn}$ and $\mathrm{Si} / \mathrm{Sn}$ atomic ratios are estimated 0.7 and 38, respectively.

\section{Hydrogen storage}

In the development of new materials for $\mathrm{H}_{2}$ adsorption, UZAR-S3 and S4 may play an important role. UZAR-S3, once has been swollen and delaminated to obtain UZAR-S4, shows a hydrogen adsorption behavior comparable to activated carbons with a high porosity development and not found for any of the previously reported 
stannosilicates. Two samples of UZAR-S4 were measured checking the reproducibility of the material in the adsorption of hydrogen at $-196{ }^{\circ} \mathrm{C}$ as shown in Fig. 8. For comparison, hydrogen adsorption isotherms of UZAR-S1, UZAR-S3 and protonated UZAR-S3 are also shown.

UZAR-S3 and protonated UZAR-S3 have a small hydrogen adsorption, and similar in both cases, because they have not been delaminated. Regarding UZAR-S1, as it has already been delaminated from JDF-L1, it has a hydrogen adsorption capacity greater (2.1 wt\% at $40 \mathrm{bar})$.

UZAR-S4 shows the maximum value of gravimetric $\mathrm{H}_{2}$ adsorption of the four materials tested being $4.2 \pm 0.1 \mathrm{wt} \%$ (average and standard deviation of two samples) at 40 bar, obtaining for 10 bar of pressure a gravimetric adsorption value of $3.7 \pm 0.1 \mathrm{wt} \%$. It is very important to note the solid density used to calculate the volumetric hydrogen storage capacities. UZAR-S4 has a high density, tap density of $0.43 \mathrm{~g} / \mathrm{mL}$ determined by filling and vibrating a container with a known weight of sample obtaining the occupied volume and crystal density of $1.67 \mathrm{~g} /$ $\mathrm{mL}$, so its total volumetric $\mathrm{H}_{2}$ storage capacity, which was calculated as the sum of the excess $\mathrm{H}_{2}$ adsorbed on the porous material and the compressed $\mathrm{H}_{2}$ as detailed in a previous work [40], is $26.2 \mathrm{~g}$ of $\mathrm{H}_{2} / \mathrm{L}$ (calculated from tap density) which is a remarkable value in terms of total storage capacity, especially taking into account that the tap density was used in the calculations. These results indicate that UZAR-S4 is an optimal material for the adsorption of $\mathrm{H}_{2}$ compared to the materials that are currently researching, as are [40]: MOF-5, $16 \mathrm{~g}$ of $\mathrm{H}_{2} / \mathrm{L}$, and activated carbons MAX3, $20 \mathrm{~g}$ of $\mathrm{H}_{2} / \mathrm{L}$ and AC-1, $23 \mathrm{~g}$ of $\mathrm{H}_{2} / \mathrm{L}$ (values for maximum volumetric hydrogen storage capacity from tap density). MOF-5, MAX3 and AC-1 shows a greater gravimetric hydrogen adsorption than UZAR-S4 (5.2, 5.3 and $5.4 \mathrm{wt} \%$ respectively) but these materials have a lower tap density than UZAR-S3 (0.30, 0.36 and $0.38 \mathrm{~g} / \mathrm{L}$ respectively) resulting smaller values of volumetric hydrogen adsorption. 
Moreover, is worth noting that UZAR-S4 with a BET surface area of $236 \mathrm{~m}^{2} / \mathrm{g}$ shows the same excess $\mathrm{H}_{2}$ adsorption that activated carbons prepared from a Spanish anthracite by chemical activation with $\mathrm{KOH}$ (KUA1) and prepared from Subituminous coal by chemical activation with $\mathrm{KOH}$ (H1) [33] which show a BET surface area of around $2000 \mathrm{~m}^{2} / \mathrm{g}$. Hydrogen adsorption measurements at $25{ }^{\circ} \mathrm{C}$ were also performed being 0.63 wt $\%$ the excess hydrogen adsorption at 200 bar. From these results, it is important to highlight that UZAR-S4 obtained a similar value than A20, commercial activated carbon fibers from Osaka Gas Co with a BET surface area close to $2000 \mathrm{~m}^{2} / \mathrm{g}$ [33].

It should be noted that, as it can be clearly seen in the UZAR-S4 material, even when the $\mathrm{H}_{2}$ pressure was reduced to 1 bar in the desorption experiment, the sample still had a very high amount of $\mathrm{H}_{2}$ adsorbed, indicating the existence of very narrow pores which could only be filled by very small adsorbates, or for those adsorbates showing an intense interaction with the adsorbent material.

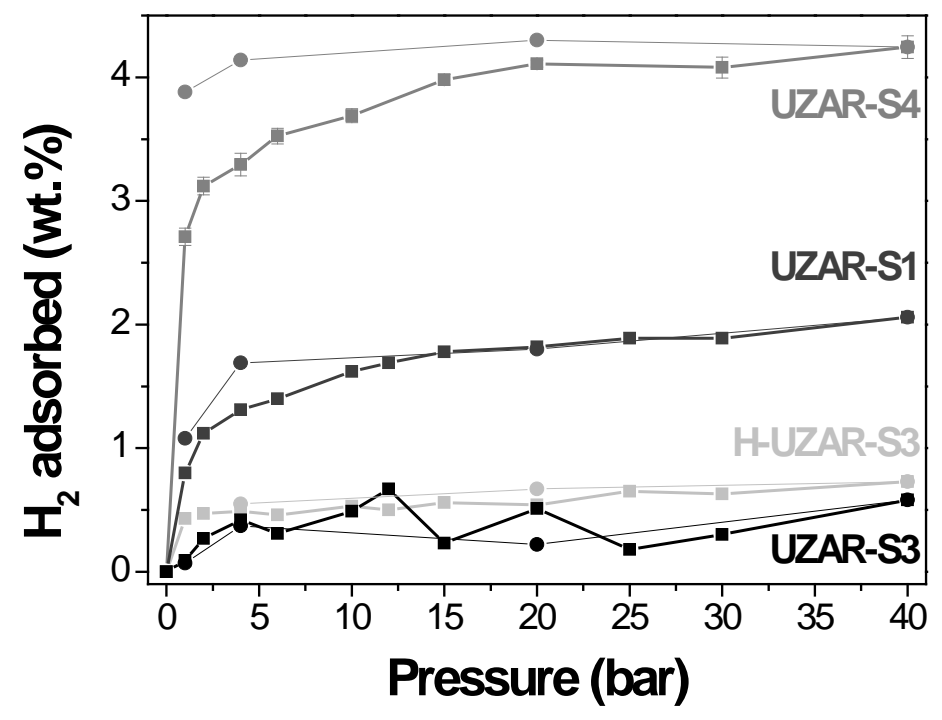

Figure 8. $\mathrm{H}_{2}$ adsorption of UZAR-S1, UZAR-S3, H-UZAR-S3 and UZAR-S4 


\section{Conclusions}

A new layered stannosilicate, named UZAR-S3, has been obtained by hydrothermal synthesis carried out at $230{ }^{\circ} \mathrm{C}$ and $96 \mathrm{~h}$. It presents a lamellar morphology and a framework composed of $\mathrm{SiO}_{4}$ tetrahedra and $\mathrm{SnO}_{6}$ octahedra. Its empirical formula is $\mathrm{Na}_{4} \mathrm{SnSi}_{5} \mathrm{O}_{14} \cdot 3.5 \mathrm{H}_{2} \mathrm{O}$. Several techniques like XRF, SEM, 29Si NMR MAS, 119Sn NMR MAS and specially XRD showed that UZAR-S3 has never been reported before.

UZAR-S3 has been protonated through an exchange procedure, where no modifications in the framework have been observed. Then it was swollen through intercalation of nonylamine molecules increasing the layers spacing from 1.3 to $3.0 \mathrm{~nm}$.

A chemical extraction with $0.1 \mathrm{M} \mathrm{HCl} /$ ethanol was carried out to delaminated the swollen UZAR-S3. The new nanometric material obtained, called UZAR-S4, has an external specific surface area of $236 \mathrm{~m}^{2} / \mathrm{g}$. NMR MAS, TGA, XRD, TEM, Hg porosimetry and adsorption of $\mathrm{N}_{2}, \mathrm{CO}_{2}$ and $\mathrm{H}_{2}$ analysis provide evidences for existence of nanometer like-high aspect ratio particles. It has been observed Sn leaching during delamination process developed with $\mathrm{HCl} /$ ethanol mixtures.

At $-196{ }^{\circ} \mathrm{C}$, UZAR-S4 presents a high $\mathrm{H}_{2}$ adsorption capacity of 3.7 and 4.2 wt\% for 10 and 40 bar, respectively. These results and its high packing density (0.43 $\mathrm{g} / \mathrm{mL}$ ) mean a higher hydrogen storage capacity (26.2 $\mathrm{g}$ of $\mathrm{H}_{2} / \mathrm{L}$ at $40 \mathrm{bar}$ ) than that for other materials currently being investigated.

\section{Acknowledgements}


The authors would like to thank the Spanish MINECO and FEDER (Project CTQ201231762). Á. Berenguer-Murcia thanks the Spanish MINECO for a Ramón y Cajal fellowship (RyC 2009-03913).

1. Rocha, J. and Z. Lin, Micro- mixed octahedral-pentahedral-tetrahedral framework silicates. Microporous and Mesoporous Mineral Phases, 2005. 57: p. 173201.

2. Anderson, M.W., et al., Structure of the microporous titanosilicate ETS-10. Nature, 1994. 367(6461): p. 347-351.

3. Philippou, A. and M.W. Anderson, Structural investigation of ETS-4. Zeolites, 1996. 16(2-3): p. 98-107.

4. Ilyushin, G.D., New data on crystal-structure of umbite $\mathrm{K}_{2} \mathrm{ZrSi}_{3} \mathrm{O}_{9} \cdot \mathrm{H}_{2} \mathrm{O}$. Inorganic Materials, 1993. 29(7): p. 1128-1133.

5. Corcoran, E.W. and D.E.W. Vaughan, Hydrothermal synthesis of mixed octahedral-tetrahedral oxides - Synthesis and characterization of sodium stannosilicates. Solid State Ionics, 1989. 32-3: p. 423-429.

6. Lin, Z., J. Rocha, and A. Valente, Synthesis and characterisation of a framework microporous stannosilicate. Chemical Communications, 1999(24): p. 2489-2490.

7. Lin, Z., et al., Synthesis and structure of a novel microporous framework stannosilicate. Journal of Materials Chemistry, 2000. 10(6): p. 1353-1356.

8. Ferreira, A., et al., Ab initio structure determination of a small-pore framework sodium stannosilicate. Inorganic Chemistry, 2001. 40(14): p. 3330-3335.

9. Lin, Z., A. Ferreira, and J. Rocha, Synthesis and structural characterization of novel tin and titanium potassium silicates $\mathrm{K}_{4} \mathrm{M}_{2} \mathrm{Si}_{6} \mathrm{O}_{18}$. Journal of Solid State Chemistry, 2003. 175(2): p. 258-263. 
10. Ferreira, A., et al., Ab initio structure determination of novel small-pore metalsilicates: knots-and-crosses structures. Inorganica Chimica Acta, 2003. 356: p. 19-26.

11. Lin, Z. and J. Rocha, Synthesis and characterisation of a stannosilicate with the structure of penkvilksite-1M. Microporous and Mesoporous Materials, 2006. 94(1-3): p. 173-178.

12. Lo, F.R. and K.H. Lii, High-temperature, high-pressure hydrothermal synthesis and characterization of a new framework stannosilicate: $\mathrm{Cs}_{2} \mathrm{SnSi}_{3} \mathrm{O}_{9}$. Journal of Solid State Chemistry, 2005. 178(4): p. 1017-1022.

13. Millini, R., et al., Synthesis, characterization and crystal structure of EMS-2 - a novel microporous stannosilicate. Microporous and Mesoporous Materials, 2007. 101(1-2): p. 43-49.

14. Corma, A., et al., Delaminated zeolite precursors as selective acidic catalysts. Nature, 1998. 396(6709): p. 353-356.

15. Choi, S., et al., Layered silicates by swelling of AMH-3 and nanocomposite membranes. Angewandte Chemie-International Edition, 2008. 47(3): p. 552-555.

16. Wang, Z. and T.J. Pinnavaia, Hybrid organic-inorganic nanocomposites: Exfoliation of magadiite nanolayers in an elastomeric epoxy polymer. Chemistry of Materials, 1998. 10(7): p. 1820-1826.

17. Andrews, S.J., et al., Piperazine silicate (EU-19) - The structure of a very small crystal determined with synchrotron radiation. Acta Crystallographica Section BStructural Science, 1988. 44: p. 73-77.

18. Schreyeck, L., et al., PREFER: a new layered (alumino) silicate precursor of FER-type zeolite. Microporous Materials, 1996. 6(5-6): p. 259-271.

19. Pergher, S.B.C., A. Corma, and V. Fornes, Preparation and characterization of MCM-22 zeolite and its layered precursor. Quimica Nova, 2003. 26(6): p. 795-802. 
20. Zanardi, S., et al., Crystal structure determination of zeolite $\mathrm{Nu}-6(2)$ and its layered precursor Nu-6(1). Angewandte Chemie-International Edition, 2004. 43(37): p. 4933-4937.

21. Blake, A.J., K.R. Franklin, and B.M. Lowe, Preparation and properties of piperazine silicate (EU-19) and a silica polymorph (EU-20). Journal of the Chemical Society-Dalton Transactions, 1988(10): p. 2513-2517.

22. Corma, A., et al., Preparation, characterisation and catalytic activity of ITQ-2, a delaminated zeolite. Microporous and Mesoporous Materials, 2000. 38(2-3): p. 301309.

23. Corma, A., et al., New aluminosilicate and titanosilicate delaminated materials active for acid catalysis, and oxidation reactions using $\mathrm{H}_{2} \mathrm{O}_{2}$. Journal of the American Chemical Society, 2000. 122(12): p. 2804-2809.

24. Corma, A., V. Fornes, and U. Diaz, ITQ-18 a new delaminated stable zeolite. Chemical Communications, 2001(24): p. 2642-2643.

25. Gorgojo, P., et al., Direct exfoliation of layered zeolite Nu-6(1). Microporous and Mesoporous Materials, 2011. 142(1): p. 122-129.

26. Rubio, C., et al., Seeded synthesis of layered titanosilicate JDF-L1. Materials Letters, 2009. 63(1): p. 113-115.

27. Lin, Z., et al., Synthesis and structural characterization of microporous umbite, penkvilksite, and other titanosilicates. Journal of Physical Chemistry B, 1997. 101(36): p. $7114-7120$.

28. Rubio, C., et al., Exfoliated Titanosilicate Material UZAR-S1 Obtained from JDF-L1. European Journal of Inorganic Chemistry, 2010. 2010(1): p. 159-163. 
29. Casado, C., et al., Synthesis, swelling, and exfoliation of microporous lamellar titanosilicate AM-4. European Journal of Inorganic Chemistry, 2011. 2011(14): p. 22472253.

30. Supronowicz, W. and F. Roessner, Influence of Sn and Al heteroatoms on the synthesis of Ilerite. Clays and Clay Minerals, 2011. 59(1): p. 95-105.

31. Jimenez, V., et al., Hydrogen storage in different carbon materials: Influence of the porosity development by chemical activation. Applied Surface Science, 2012. 258(7): p. 2498-2509.

32. Jorda-Beneyto, M., et al., Advanced activated carbon monoliths and activated carbons for hydrogen storage. Microporous and Mesoporous Materials, 2008. 112(1-3): p. 235-242.

33. Jorda-Beneyto, M., et al., Hydrogen storage on chemically activated carbons and carbon nanomaterials at high pressures. Carbon, 2007. 45(2): p. 293-303.

34. Rowsell, J.L.C., et al., Hydrogen sorption in functionalized metal-organic frameworks. Journal of the American Chemical Society, 2004. 126(18): p. 5666-5667.

35. Wong-Foy, A.G., A.J. Matzger, and O.M. Yaghi, Exceptional $\mathrm{H}_{2}$ saturation uptake in microporous metal-organic frameworks. Journal of the American Chemical Society, 2006. 128(11): p. 3494-3495.

36. Anson, A., et al., Adsorption of carbon dioxide, ethane, and methane on titanosilicate type molecular sieves. Chemical Engineering Science, 2009. 64(16): p. 3683-3687.

37. Sebastian, V., et al., Deeping into the microporosity of porous silicates Ti-and Sn-umbite. Microporous and Mesoporous Materials, 2011. 142(2-3): p. 649-654.

38. El Mouzdahir, Y., et al., Synthesis of nano-layered vermiculite of low density by thermal treatment. Powder Technology, 2009. 189(1): p. 2-5. 
39. Julve, D., et al., Analysis of mercury porosimetry curves of precipitated silica, as an example of compressible porous solids. Journal of Non-Crystalline Solids, 2011. 357(4): p. 1319-1327.

40. Marco-Lozar, J.P., et al., MOF-5 and activated carbons as adsorbents for gas storage. International Journal of Hydrogen Energy, 2012. 37(3): p. 2370-2381. 